\title{
Epidemiology of Salmonella Associated Diarrhea in Children in Faisalabad, Pakistan
}

\author{
Muhammad Usman ${ }^{1}$ Nabeela Mukhtar ${ }^{2}$ \\ ${ }^{1}$ Institute of Microbiology, University of Agriculture, Faisalabad, Pakistan \\ ${ }^{2}$ Department of Wild life Fisheries, Government college university Faisalabad, 38000
}

\begin{abstract}
The present project was designed to study the epidemiology of salmonella associated diarrhea in children in Faisalabad, Pakistan. In this case control study, stool samples of 300 children having age below 60 months were collected from different health centers of Faisalabad (150 of the children having diarrhea and 150 without diarrhea). These samples were evaluated for the presence of salmonella through specific culture media, staining reaction, biochemical tests and sugar fermentation characteristics. Epidemiological data of each child were collected on a predesigned questionnaire. Data obtained was analyzed through chi-square. Out of 150 diarrhoeal samples, 21(14\%) Salmonella were isolated. While out of 150 control samples, 5 (3.3\%) Salmonella isolates were obtained. O.R was equal to $4.720(p<0.05)$. O.R shows that number of positive salmonella were 4.72 times more in diarrhoeal than control. Number of diarrhoeal children were more in those families where filtered water was not used and where latrine facilities were not present. It was noted that children of those families were more prone to diarrhea where mothers did not wash their hands before feeding. Low level of education and lackness of information on health and sanitation requirements also have impact on occurrence of diarrhoea. Not only attempts must be made to reduce the prevalence of diarrhoea but also we need to work on the related factors responsible for diarrhoea. Recommendations for further studies, more epidemiological studies should be directed towards the prevalence of this organism, so that a better control strategy should be made on national level to control diarrhea.
\end{abstract}

Key Words: Age, Diarrhoea, Epidemiology, Faisalabad, Salmonella,

\section{Introduction}

Diarrhoeal disease is one of the major and leading causes of illness in young children in developing countries [1]. Diarrhoeal diseases are the major causes of childhood morbidity and mortality in developing as well developed countries. 500 million cases of acute diarrhoeal episodes occur every year in children which are under 5 years throughout the world [2).

Diarrhoea is a major cause of death among young children in low-income countries. Diarrhoea decreases the absorption of nutrients and results in poor growth in children, and also reduces resistance to infection, and ultimately there is long term gut disorders. Diarrhoea ranks at the third number as a major cause of mortality and morbidity among infectious disease (after respiratory infections and HIV/AIDS), placing it above tuberculosis and malaria. Young children and infants bear $68 \%$ of the total burden of diarrhoeal disease [3].

Diarrhea accounts for $17 \%$ of all deaths among children which are less than five years of age. Annually, at least 1,500 million cases of diarrhoea occur in children which are less than 5 years of age every year and there are 4 million deaths due to diarrhea [3].

The public health significance of diarrhoeal disease cannot be overemphasized. Due to diarrhoeal diseases there are almost 3 million deaths every year mainly among children which are less than five years of age [4]. Mortality due to diarrhoea in children less than five years of age in Africa has been estimated at about 106 per 1000 [5]. Reports from Nigeria indicate that more 315,000 deaths of preschool age children are recorded every year due to diarrhoeal disease [6,7].

The contribution of the various pathogens to diarrhoea may differ substantially between regions depending on local meteorological, geographic, and socio-economic conditions [8]. Reasons of diarrhoeal diseases are poor hygiene and sanitation, non availability of safe drinking water as well as inadequate education of health care providers and recipients $[9,10]$. Acute diarrhoea due to bacterial infections is an important and major cause of morbidity and mortality in infants and young children in most developing countries [11]. Salmonella is one of the bacteria which causes gastroenteritis in infants and children [12].

Out of the total population of Pakistan, $45 \%$ are under 14 years and $18 \%$ under 5 years of age. Most prominent and presenting complaint in this age group especially during summer is diarrhoea. It is estimated that about 13 million episodes of diarrhea occur every year among school children alone in the country and about 0.1 million deaths occur every year. The most common cause of death in children under 1 year is diarrhea and this is 
responsible for more than $45 \%$ of deaths in this age group directly or indirectly. Mostly deaths occur due to the sever dehydration associated with malnutrition [13].

\section{Materials And Methods}

The present project was designed to study the epidemiology of salmonella associated diarrhea in children in Faisalabad, Pakistan. Stool samples of 300 children from different health centers of Faisalabad were collected randomly (150 diarrheal and 150 non-diarrheal). Samples were collected in clean plastic bags. A maximum of 10 samples for a week were obtained from different health centers of Faisalabad. Samples were tested at least 2-4 hours after collection in laboratory. All glasswares including test tubes, petriplates and flasks were sterilized in hot air oven at $171{ }^{\circ} \mathrm{C}$ for 60 minutes. After 60 minutes, tray was removed from hot air oven. All the glassware was kept unopened till required for sampling. Culture media (selenite broth) were also sterilized at a temperature of $121^{\circ} \mathrm{C}$ for $15-20 \mathrm{~min}$ at $15 \mathrm{lb}$. [14].

\section{Isolation and Identification of Salmonella}

Stool samples were pre-enriched in selenite broth and incubated for 18 hours at $35^{\circ} \mathrm{C}$. [15] After this isolation through selective medium were done. Salmonella shigella (SS) agar were used for selective isolation of salmonella. The inoculating loop were sterilized on burner flame and samples from selenite broth were streaked on SS agar and incubated at $37{ }^{\circ} \mathrm{C}$ for $24-48$ hours [16]. After $24-48$ hours of incubation, the cultural characteristics including size, shape, color and texture of colonies were observed. Colonies of Salmonella were colorless with black centers [17].

Morphological characteristics of bacteria were examined under microscope after Gram staining. Most of isolates appeared to be bacilli, Gram negative short thin rods [17]. Motility of salmonella was checked [18]. The isolates were biochemically characterized by sugar fermentation tests and these tests include glucose, lactose, sucrose, mannitole, mannitole, mannose, inositole, raffinose, rabinose and dulcitole. Other tests includes urea test, lysine decarboxylation test, ornithin decarboxylation test, $\mathrm{H}_{2} \mathrm{~S}$ production test, catalase test and IMVC (Indole, Methyl red, Voges Proskauser and citrate utilization) [19]. Indole reduction and voges prosker tests were negative. Methyl red and citrate utilization tests were positive. Glucose, fructose, maltose and mannitole fermentation tests were positive for acid and gas production. Whereas lactose and sucrose fermentation tests were negative as there was no gas production and no change in colour of medium.

\section{Results And Disscussion}

The study was carried out in Epidemiology and Public Health Lab, Institute of Microbiology, University of Agriculture Faisalabad during 2011. The aim was to study the Epidemiology of Salmonella associated diarrhea in children in Faisalabad. Stool samples of 300 children (aged matched) from different health centers of Faisalabad were collected randomly (150 diarrheal and 150 non-diarrheal). The results of the experiment are interpreted and discussed as follows:

\section{Samples Positive for Salmonella}

Out of 150 diarrhoeal samples, 21 (14\%) were positive for Salmonella. While out of 150 control samples, only $5(3.33 \%)$ were positive for Salmonella. The collected data were subjected to appropriate statistical analysis. Chi square test was applied. The level of significance was $(\mathrm{p}<0.05)$.

Table 1. Total prevalence of Salmonella in diarrhoeal children

\begin{tabular}{|l|l|l|}
\hline Total samples & No. of positive salmonella & \% age \\
\hline 150 & 21 & 14 \\
\hline
\end{tabular}

Table 2. Total prevalence of Salmonella in control children

\begin{tabular}{|l|l|l|}
\hline \multicolumn{1}{|c|}{ Total samples } & No. of salmonella positive & \% age \\
\hline 150 & 5 & 3.33 \\
\hline
\end{tabular}

Table 3. Odd's Ratio

\begin{tabular}{|c|c|c|c|}
\hline & Diseased & Control & Total \\
\hline $\begin{array}{c}\text { Salmonella } \\
\text { Positive }\end{array}$ & 21 & 5 & 26 \\
\hline $\begin{array}{c}\text { Salmonella } \\
\text { Negative }\end{array}$ & 129 & 145 & 274 \\
\hline Total & 150 & 150 & 300 \\
\hline
\end{tabular}

$\mathrm{O} . \mathrm{R}=21 * 145 / 5 * 129=3045 / 645=4.720$

$\mathrm{O} . \mathrm{R}=4.720(\mathrm{p}<0.05)$

O.R shows that number of positive salmonella are 4.72 times more in diarrhoeal than control. 
Table 4. Detection of Salmonella from diarrhoeal children up to five years.

\begin{tabular}{|c|c|c|c|}
\hline Age (Months) & No. of Samples & No. of positive Slmonella & \% age \\
\hline $0-12$ & 59 & 16 & 10.66 \\
\hline $13-24$ & 31 & 2 & 1.33 \\
\hline $25-36$ & 26 & 2 & 1.33 \\
\hline $37-48$ & 18 & 1 & 0.66 \\
\hline $49-60$ & 16 & 0 & 0 \\
\hline Total & 150 & 21 & 14 \\
\hline
\end{tabular}

$$
\text { Chi-sq }=10.68 \quad \mathrm{DF}=4 \quad \mathrm{p} \text {-value }=0.03
$$

Table 5. Detection of Salmonella from diarrhoel children adapting different feeding

\begin{tabular}{|c|c|c|c|}
\hline Feeding & No. of Samples & No. of positive salmonella & \% age \\
\hline Breast fed & 47 & 2 & 1.33 \\
\hline Others & 103 & 19 & 12.67 \\
\hline Total & 150 & 21 & 14 \\
\hline \multicolumn{4}{r}{ Chi-sq=4.268 } \\
\hline
\end{tabular}

Table 6. Detection of Salmonela from control children adapting different feeding

\begin{tabular}{|c|c|c|c|}
\hline Feeding & No. of Samples & No. of positive Salmonella & \% age \\
\hline Breast fed & 90 & 1 & 0.67 \\
\hline Others & 60 & 4 & 2.67 \\
\hline Total & 150 & 5 & 3.33 \\
\hline
\end{tabular}

Table 7. Detection of Salmonella from diarrhoeal children, families of which used filtered and unfiltered water.

\begin{tabular}{|c|c|c|c|}
\hline Water resource & No. of Samples & No. of positive Salmonella & \% age \\
\hline Filtered & 58 & 4 & 2.67 \\
\hline Unfiltered & 92 & 17 & 11.33 \\
\hline Total & 150 & 21 & 14 \\
\hline Chi-sq $=3.06$ & DF $=1$ & p-value $=0.08$ &
\end{tabular}

Table 8. Detection of Salmonella from control children, families of used filtered and unfiltered water.

\begin{tabular}{|c|c|c|c|}
\hline Water resource & No. of Samples & No. of positive Salmonella & \% age \\
\hline Filtered & 105 & 2 & 1.33 \\
\hline Unfiltered & 45 & 3 & 2.0 \\
\hline Total & 150 & 5 & 3.33 \\
\hline
\end{tabular}

Chi-sq=2.03 $\quad \mathrm{DF}=1 \quad \mathrm{p}$-value $=0.15$

Table 9. Detection of Salmonella from diarrhoel children who's mothers wash and did not wash their hands.

\begin{tabular}{|c|c|c|c|}
\hline $\begin{array}{c}\text { Hygiene } \\
\text { conditions }\end{array}$ & No. of Samples & No. of positive Salmonella & \% age \\
\hline Hand washing & 60 & 3 & 2.0 \\
\hline $\begin{array}{c}\text { No hand } \\
\text { washing }\end{array}$ & 90 & 18 & 12.0 \\
\hline Total & 150 & 21 & 14 \\
\hline
\end{tabular}

Chi-sq= 5.23

\begin{tabular}{l|l}
150 & \\
$\mathrm{DF}=1$ & $\mathrm{p}$-value $=0.02$
\end{tabular}

Table 10. Detection of Salmonella from control children whose mothers wash and did not wash their hands.

\begin{tabular}{|c|c|c|c|}
\hline $\begin{array}{c}\text { Hygiene } \\
\text { conditions }\end{array}$ & No. of Samples & No. of positive Salmonella & \% age \\
\hline Hand washing & 78 & 0 & 0 \\
\hline $\begin{array}{c}\text { No hand } \\
\text { washing }\end{array}$ & 72 & 5 & 3.33 \\
\hline Total & 150 & 5 & 3.33 \\
\hline
\end{tabular}

$\begin{array}{lll}\text { Chi-sq }=5.23 & \mathrm{DF}=1 & \mathrm{P} \text {-value }=0.022\end{array}$




\section{Graph showing the number of positive salmonella in diseased and control}

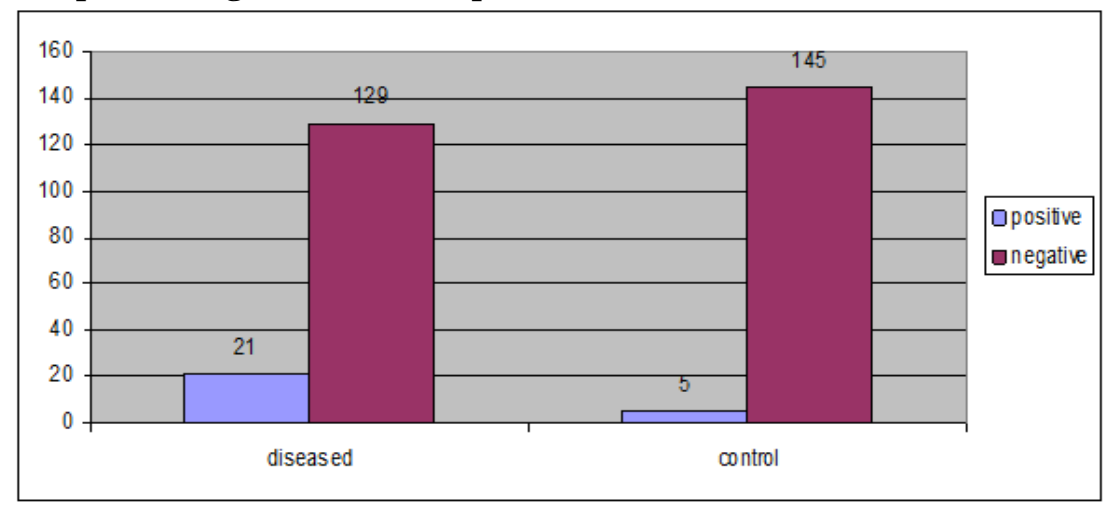

300 subjects were studied belonging to Faisalabad (150 diarrhoeal children and 150 controls). All children were less than 5 years. Age Stratification of children with dirrhoea from civil hospital is shown in table number 4. Out of 150 diarrhoeal children, 59 (39.33\%) were less 1 year old and of these $16(10.66 \%)$ were positive for Salmonella. $31(20.67 \%)$ were less than two years old and of these $2(1.33 \%)$ were positive for Salmonella. This showed that as the age of children increased the prevalence of diarrhea decreased $(p=0.03)$. As the $\mathrm{p}<0.05$, it indicates that a significant difference is found between age of the children and occurrence of diarrhea. Our results are also coincide with the findings of [20], who found that the prevalence of Salmonella was high in children less than 2 years of age both in diarrhoea and control group. The children which were only breast fed have less chance of diarrhea and the prevalence of Salmonella was also less as compared to other fed. Table 5 is showing that only $2(1.33 \%)$ samples were positive for Salmonella out of 47 breast fed child but in case of those children nourished from other sources, $19(12.67 \%)$ Salmonella isolates were obtained $(p=0.038)$. [21] also observed significant effect of feeding on prevalence of Salmonella. Table 7 is showing that, out of 150 diarrhoeal children, $58(38.66 \%)$ used the filtered water and of these 4 (2.67\%) were positive for Salmonella. The remaining $92(61.33 \%)$ used the unfiltered water and of these $17(11.87 \%)$ were positive for Salmonella. P value was 0.080 . The hand washing habits of the mothers before feeding their children is of particular interest, because it was at this time that the child was particularly vulnerable to the transmission of pathogens. There is a significant difference between number of positive Salmonella and number of negative Salmonella in case of hand washing habit for diarrhoeal conditions as shown in table $9(\mathrm{p}=0.02)$.

This indicates that hygienic conditions are closely related to the occurrence of diarrhea. With the improvement of hygienic conditions, the chances of occurrence of diarrhea can be decreased. [22] found that by applying hand washing and other hygienic conditions transmission ways of many pathogens to the hosts can be blocked. Many studies have been conducted on hand washing in accordance its effects on diarrhea and it was reported that diarrhoeal morbidity was reduced by applying this condition. The similar results were also observed in a study done by [23] in Vietnam. Data is showing that number of diarrhoeal children is more in those families where filtered water is not used and where latrine facilities are not present. By different literatures, it has been noted that children are more prone to diarrhea where mothers do not wash their hands before feeding. Low level of education and lackness of information on health and sanitation requirements also have impact on occurrence of diarrhoea. [24] have suggested, based upon the work of [25], that low-weight babies who attain relative affluence in later life are more susceptible to certain diseases (cardio-vascular, diabetes) than low-weight babies who do not attain such levels of affluence. They explain this by saying that "when faced with inadequate access to nutritional resources (owing to maternal under nutrition) the fetus undergoes an adaptive mechanism in its physiology as well as metabolic processes. This adaptation hampers its ability to cope with conditions of relatively plenty that might be encountered in later life". A similar mechanism might be at work with the incidence of diarrhea in young children.

\section{Conclusion}

Not only attempts must be made to reduce the prevalence of diarrhoea but also we need to work on the related factors responsible for diarrhoea. Moreover it is also recommended that more epidemiological investigations should be directed towards the prevalence of this organism, so that a batter control strategy should be made on national level for hygienic conditions. Research should be focused on development of recombinant vaccine against Salmonella by using local strains.

\section{Acknowledgment}

The authors would like to thank Professor Ch. Mukhtar Ali Gill (District Education Officer Sheikhupura) for providing us financial support. 


\section{Refrences}

[1]. U Parashar, JS. Bresee and RI. Glass, The global burden of diarrhoeal disease in children. Bull. World Health Organ, 2003 , 81: 236.

[2]. A Walsh and S. Warren. Selective primary health care: an interim strategy for disease control in developing countries. N Engl J Med, 1979, 301, 967-974.

[3]. J Bartram, "New water forum will repeat old message". Bulletin of the World Health Organization, $2003,83(3), 158$.

[4]. Anonymous, Selected publications and documents on diarrhoeal diseases (including cholera), 1999, 25-26.

[5]. C Seung-Hak, K. Jong-Hyun, K. Jong-Chul, S. Hyun-Ho, K. Yeon-Ho and L. Bok-Kwon, Surveillance of Bacterial Pathogens Associated with acute diarrheal disease in the Republic of Korea during one year 2003.The Journal of Microbiology, 2006, 44(3), 327-335.

[6]. OA Olowe, AB. Olayemi, KIT. Eniola and AO. Adeyeba, Aetiological agents of diarrhoea in children under 5 years of age in Osogbo. Afr. J. Clin. and Exp. Microbiol, 2003, 4(3), 62- 66.

[7]. SA Alabi, RA. Audu, KS. Oyedeji, AG. Mafe and JE. Uhuangho, Viral, bacterial and parasitic agents associated with infantile diarrhea in Lagos. Nig J Med Res, 21998 (1/2), 29-32.

[8]. OA Babaniyi, Oral Dehydration of Children with Diarrhea in Nigeria, A 12 Year Renew Of Impact on Morbidity and Mortality from Diarrhea Disease and Diarrhea Treatment Practices. J Trop Paediat, 1991, 37, 16-66.

[9]. K Reither, R. Ignatius, T. Weitzel, A. SeiduKorkor, L. Anyidoho, E. Saad, A. Djie-Maletz, P. Ziniel, F. Amoo-Sakyi, F. Danikuu, S. Danour, RN. Otchwemah, E. Schreier, U. Bienzle, K. Stark and FP. Mockenhaupt, Acute childhood diarrhoea in northern Ghana: epidemiological, clinical and microbiological characteristics. BM C Infectious Diseases, 2007, 7, 104-107.

[10]. V Curtis, S. Cairncross and R. Yonli, Domestic hygiene and diarrhea-pinpointing the problem Trop. Med. Int. Health, 2000, 5(1), 22-32.

[11]. N Thapar and IR. Sanderson, Diarrhoea in children: an interface between developing and developed countries. Lancet; 2004, 363, 641-653.

[12]. DV Adegunloye, African Journal of Biotechnology, 5 (2), 2005, 162-164.

[13]. Ossuna, MM. Dubowitz, j. Hutcheson, JB. Howard and RH. Starr, "A Randomized Clinical Trial of Home Intervention for Children with Failure to Thrive." Pediatrics, 2005, 95, 807-811.

[14]. MA Khan, M. Abdur-Rab, N. Israr, M. Ilyas, F. Ahmad, and Z. Kundi, Transmission of Salmonella Worthington by oropharyngeal suction in hospital neonatal unit. Pediatr Infect Dis J, 1983, 10, 668-672.

[15]. R Cruiskshank, RP. Duguid, BP. Marmion and RHA. Swain, Medical Microbiology, 1975, 2, 12th Edition. Churchill Livingstone, New York.

[16]. A Johargy, H. Ghazi, A. Mumenah, Frequency of viral, bacterial and parasitic enteropathogens among Young children with acute diarrhoea in Saudi Arabia. JPMA, 2010, 60, 456.

[17]. I Mikhail, E. Fox, L. Richard, Haberberger, MH. Ahmed and EA. Abbatte, Epidemiology of Bacterial Pathogens Associated with Infectious Diarrhea in Djibouti. J. clin micro, 1990, 956-961.

[18]. Anonymous, Laboratory Protocol WHO GSS- South America- Institute Malbran, Argentina, 2008, 22-23.

[19]. PR Edwards, and WH. Ewing, Identification of Enterobacteriaceae, 2nd ed. Burgess Publishing Co., Minneapolis 1962.

[20]. Anonymous, Laboratory Protocol: Isolation of Salmonella, $5^{\text {th }}$ Edition, 2007, 15-16.

[21]. K Trung, GD. Fang, AA. Lima, CV. Martins, JP. Nataro and RL. Guerrant, Etiology and epidemiology of persistent diarrhea in northeastern Brazil: a hospital-based, prospective, case-control study. J Pediatr Gastroenterol Nutr, 2006, 21, $137-144$.

[22]. BA Hoque, T. Juncker, RB. Sack, M. Ali and KM. Aziz, Sustainability of a water, sanitation and hygiene education project in rural Bangladesh: a 5-year follow-up. Bull World Health Organ, 1996, 74, 431-437.

[23]. TV Nguyen, LP. Van, LC. Huy, KN. Gia and A. Weintraub, Detection and characterization of diarrheagenic Escherichia coli from young children in Hanoi, Vietnam. J. Clin. Microbiol, 2005, 43, 755-760.

[24]. S Osmani, and A. Sen, The hidden penalties of gender inequality: fetal origin of ill health. Economics and Human Biology, 2003, 1, $105-121$.

[25]. DJP Barker, Mothers, Babies and Diseases in Later Life. Churchill Livingstone, London. Econ. J, 1998, 108, $1733-1749$. 